\title{
VISUAL DEFICITS CAUSED BY REFRACTIVE ERRORS IN SCHOOL AND PRESCHOOL CHILDREN
}

\author{
Ejup Mahmudi ${ }^{1^{*}}$, Alketa Tandili², Sulejman Zhugli ${ }^{2}$, Artan Simaku ${ }^{3}$, Redi Hoxha ${ }^{4}$ \\ ${ }^{1 *}$ Regional Hospital of Tetovo, Eye Department, Macedonia; \\ ${ }^{2}$ University Hospital Center "Mother Theresa", Tirana, Albania; \\ ${ }^{3}$ Institute of Public Health, Tirana, Albania; \\ ${ }^{4}$ Directorate of Public Health, Tirana, Albania;
}

"Corresponding Author Ejup Mahmudi, e-mail: ejupmahmudi@yahoo.com;

Received July 2020; Accepted August 2020; Published September 2020;

DOI: https://doi.org/10.31407/ijees10.319

\begin{abstract}
Anomalies of refraction are the leading cause of low visual acuity in children. They can decrease the visual acuity for near (hypermetropia), for far (myopia) or for both (astigmatism). Their serious consequences are strabismus and amblyopia. The aim of the study is to measure the prevalence of anomalies of refraction. It is a transversal type of study, where were included 3-9 years old children in urban and rural area of the city of Tetovo, Macedonia. In the study participated 1848 children, 917 (49.6\%) from them were females and $931(50.4 \%)$ were males. 858 (46.4\%) belonged to preschool agegroup 3-5 years and 990 (53.6\%) to agegroup 6-9 years. Anomalies of refraction were found in $226(12.2 \%)$ of children $(95 \%$ CI10.74 - 13.77). Prevalence of anomalies of refraction $12.3 \%$, from which $10.3 \%$ preschool children and $13.9 \%$ among school children. Prevalence of anomalies of refraction was $11.9 \%$ in females and $12.6 \%$ in males. Prevalence of Astigmatism was 5.5\%, Hypermetropia 4.0\% and Miopia 2.8\%. Miopia was found more prevalent in 6-9 years old children. Anomalies of refraction and their consequences, amblyopia and strabismus should be diagnosed and treated in early childhood.
\end{abstract}

Key words: children, refractive error, screening, vision 